\title{
El área urbana funcional de Madrid (1991-2011) \\ Metodología y resultados de una propuesta de delimitación y caracterización multicriterio
}

Madrid functional urban area (1991-2011)

A multi-criteria proposal on demarcation and characterisation. Methodology and results

\section{José Manuel Gómez Giménez *}

Fecha de superación del Tribunal Fin de Máster: 22.07.2016

Tutor: Agustín Hernández Aja

\section{Resumen}

Esta investigación centra su atención en el análisis de los procesos constitutivos de lo urbano, más allá de las delimitaciones territoriales administrativas. Es fundamental arrojar luz sobre dichos procesos para estudiar las dinámicas y disyuntivas que enfrentan nuestros desiguales territorios urbanos. Con esta visión se propone una metodología para delimitar el área urbana funcional de Madrid y establecer sobre ella una diferenciación zonal que conjugue la existencia de un gradiente de intensidad de sus procesos constitutivos con la fracturación social de su espacio. Por último, un análisis multicriterio, a través de la generación de índices sintéticos, comparativos entre las diferentes zonas demarcadas, aportará una base descriptiva sobre la que evaluar tanto el acierto metodológico de la delimitación y caracterización del área funcional como su modelo evolutivo de desarrollo durante las últimas dos décadas. Los datos obtenidos arrojan luz sobre la validez de la tradicional dicotomía madrileña noroeste-sureste, así como, sobre la insostenibilidad del modelo en generación.

\section{Palabras clave}

Territorio urbano; urbanización extensiva; movilidad; segregación espacial; ocupación insostenible; vulnerabilidad.

\begin{abstract}
This research focuses on the analysis of constitutive urban processes rather than preconceived demarcations of urban sites. This is of paramount importance to cast further light on the dynamics and dilemmas which our unequal urban territories are facing. With this view, the research proposes a methodology to identify geographically Madrid's functional urban area and stablish it distinct zones. This task of zoning combines the existence of an intensity gradient in its constitutive urban processes with the social-spatial segregation pattern of Madrid. After that, a multi-criteria analysis through comparative synthetic indexes will lay the foundation for evaluating the methodology being followed heretofore and the characterization of the functional urban area. Finally, all outcomes will provide us with enough information to express a reasoned judgement on the evolutionary development of the area over the past two decades. The conclusion is the validity of the traditional segregation pattern, as well as the unsustainability of the current model set out in the area.
\end{abstract}

\section{Keywords}

Urban territories; extended urbanization; mobility; social-spatial segregation; unsustainable land use; vulnerability.

\footnotetext{
- José Manuel Gómez Giménez es alumno de postgrado del Departamento de Urbanística y Ordenación del Territorio de la Escuela Superior de Arquitectura. Universidad Politécnica de Madrid, josmangogi@gmail.com
} 


\section{Preguntas e hipótesis}

Las clasificaciones de los asentamientos humanos en función del tamaño poblacional contenido en sus límites administrativos deben ser utilizadas con cautela. No tienen nada que ver los procesos y disyuntivas que enfrenta un núcleo de 1.000 habitantes en la sierra madrileña con los de otro con la misma población en la Extremadura rural. Como tampoco se pueden comparar las dinámicas urbanas que enfrentan Leganés y Almería, aunque ambos municipios contengan una población similar en torno a los 200.000 habitantes. A priori, no se puede asumir que una población parecida indique similitudes en cuanto a los dilemas y necesidades que enfrentan dichos asentamientos. En este sentido, frases grandilocuentes como aquellas de ONU HABITAT sobre que "el futuro de lo urbano está marcado por el devenir de las ciudades intermedias" solo pueden ser proclamadas con muchas reservas.

Por el contrario, los procesos contextuales a los que se enfrentan los diferentes territorios urbanos pueden constituir un buen complemento para entender mejor los cambios que están enfrentando nuestros territorios. En este sentido, continuando con el ejemplo de Leganés y Almería, la primera se inserta en un contexto de subordinación a la aglomeración madrileña de la que forma parte mientras que la segunda desempeña un papel de cabecera en su propia aglomeración urbana, con una muy distinta caracterización de los procesos urbanos que la definen. 0 , mientras que un núcleo de 1.000 habitantes de la sierra madrileña se encuentra más o menos asimilado en el área funcionalmente dependiente de Madrid, uno extremeño forma parte de esos bordes urbanos otrora rurales.

Por otro lado, en la actualidad, el devenir de lo urbano ha dejado en muchos casos hueca la validez de las delimitaciones administrativas de la planta municipal. Realidades como las conurbaciones y las grandes áreas metropolitanas escapan de una mirada centrada en los límites administrativos, y los procedimientos aún centrados en dicho paradigma -como una planificación municipal que obvia su contexto- no sólo hacen un flaco favor en el interior de dichos municipios, sino que pueden repercutir negativamente en el territorio urbano en que se encuentran insertos.

Todo ello nos conduce a definir cuatro hipótesis centrales a cotejar durante el desarrollo de esta investigación:

Primero, ¿cuál sería el proceso contextual que caracteriza el presente de la aglomeración urbana madrileña? La dicotomía entrelazada entre concentración y urbanización extensiva. La producción espacial de un núcleo con gran densidad de actividades y flujos que genera un área de influencia, funcionalmente dependiente, sobre un fluido espacio territorial cada vez más dilatado. Este conjunto sería un área urbana funcional, concepto en el que se profundizará más adelante.

Segundo, ¿continúa siendo válida la tradicional división social del espacio madrileño entre los arcos noroeste y sureste? Aun tratándose de una simplificación tosca y que admite importantes matizaciones, todavía es una dicotomía válida para entender la aglomeración urbana de Madrid. Baste observar la abrumadora diferencia entre un noroeste metropolitano definido por un paisaje que aún conserva su atractivo natural y calidad medioambiental, y un sureste metropolitano aún hoy eminentemente agrario.

Tercero, ¿cómo ha evolucionado dicha aglomeración urbana en cuanto a su modelo de ocupación del suelo? En este caso se asume que encontraremos datos contradictorios y una gran dificultad para emitir un dictamen concluyente. De cualquier modo, partimos de datos que ponen seriamente en cuestión la sostenibilidad del modelo evolutivo, con un crecimiento caracterizado 
EL ÁREA URBANA FUNCIONAL DE MADRID (1991-2011).

METODOLOGÍA Y RESULTADOS DE UNA PROPUESTA DE DELIMITACIÓN Y CARACTERIZACIÓN MULTICRITERIO Territorios en Formación | 2017 | N11 | TRABAJOS FIN DE MÁSTER - Estudios Urbanos

por el "sprawl" y una política de transporte centrada en la sobrecualificación del sistema de movilidad rodada a través de numerosos desdoblamientos de vías convencionales y la aparición de nuevas opciones que benefician al automóvil como las autopistas radiales.

Cuarto y último, ¿existen patrones consolidados de vulnerabilidad urbana en la aglomeración urbana de Madrid? ¿Cómo han evolucionado? Toda gran aglomeración urbana, convertida en sumidero de flujos y servicios, es un lugar privilegiado en base a la gran cantidad de posibilidades que ofrece su alta concentración de actividad. Sin embargo, muchos analistas urbanos avisan del peligro de que nuestras ciudades se conviertan en lugares donde la exclusión social crece invisibilizada por las barreras de la segregación espacial. Como postula SASSEN (2014), nos encontramos ante dicotomías cada vez mayores: mientras nuestros centros urbanos parecen tener un aspecto cada vez más saludable, las periferias contienen una desigualdad invisible a los ojos del visitante exterior. Madrid no escapa a estas dinámicas y la intención de este análisis será evaluarlas y discernir hasta qué punto guardan relación con la división social del espacio madrileño, propuesta más arriba.

\section{Objetivos y metodología}

La presente investigación ha seguido un proceso de análisis con dos objetivos principales claros: la delimitación de los límites de la "aglomeración urbana" madrileña y el análisis de su caracterización y evolución en base a una división zonal propuesta.

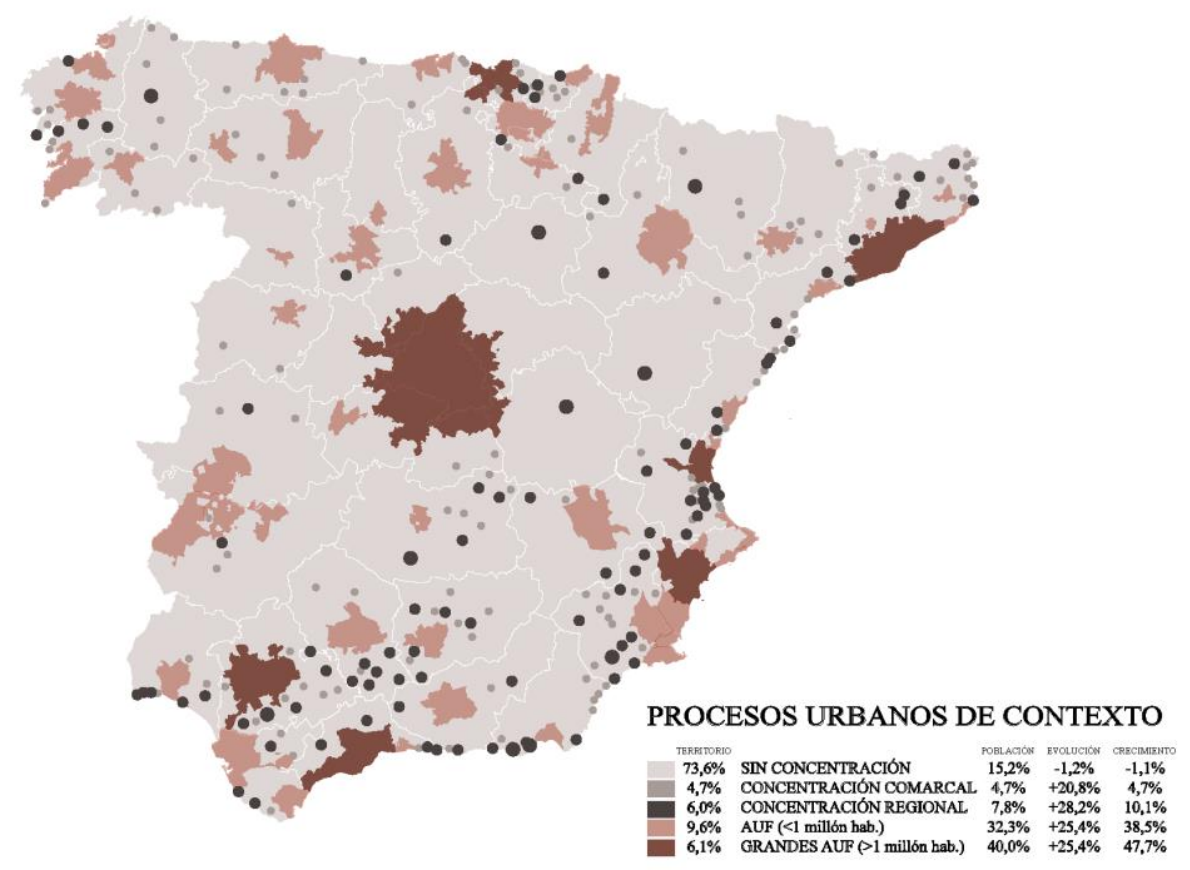

Figura 1: Procesos contextuales de los urbano en España. (Fuente: MIN. DE FOMENTO, 2015 y EUROSTAT, 2016)

En primer lugar, se desarrolla el marco de análisis a través del cual se determinará y delimitará el objeto de estudio de esta investigación: el Área Urbana Funcional de Madrid, A.U.F.M. en adelante. El enfoque abordado para tal fin tratará de reexaminar el hecho urbano desde una perspectiva centrada en los procesos contextuales. Para ello se han establecido los principales procesos urbanos observados en España (ver Fig. 1): la ausencia de concentración de servicios en la mayor parte del territorio, la concentración de servicios a escala comarcal o regional, y la 
generación de áreas funcionales de integración laboral. Una vez evaluada la pertinencia del enfoque, éste se aplicará en la delimitación y zonificación del A.U.F.M. según la intensidad de los procesos urbanos que la significan.

En segundo lugar, el análisis del A.U.F.M buscará como resultados su caracterización en base a la división zonal previamente determinada, una evaluación de su coherencia interna, así como, obtener conclusiones a la vista de los cambios observados en el periodo de estudio, de 1991 a 2011. Para ello se han llevado a cabo cinco análisis centrados en variables físicas asociadas a la disciplina urbanística. El primero evalúa los cambios en las coberturas del suelo, así como la capacidad de atracción demográfica de las diferentes zonas del área funcional durante dicho periodo. Todo ello, en contraposición a la territorialización de la vitalidad urbana entendida como concentración de actividad en relación a la población. El segundo valora la movilidad en el área de acuerdo a sus tiempos y sistemas, así como sus consecuencias sobre el "modelo de ciudad". El tercero analiza indicadores relacionados con el parque residencial, presuponiendo que sus características son, en cierta medida, una proyección de la división social del espacio. El cuarto se concentrará en evaluar los cambios en el modelo de ocupación del suelo urbano -su densidad y distribución- a lo largo de las dos décadas que comprende el periodo de estudio. En último lugar, el quinto análisis se fija como meta estudiar los cambios cuantitativos y espaciales en algunos indicadores de la vulnerabilidad urbana.

Con respecto a la delimitación y zonificación del A.U.F.M., los datos en que se ha basado este trabajo parten del monográfico elaborado por la Dirección General de Estadística del AYUNTAMIENTO DE MADRID (2014) para el trigésimo noveno Barómetro de Economía de la Ciudad de Madrid, titulado "Dimensión territorial y socioeconómica de la Región Metropolitana de Madrid". La segunda de las partes, la caracterización del A.U.F.M, se ha centrado en la consecución de varios índices sintéticos para cada una de las zonas del área en los diferentes subapartados que se examinan. Las fuentes primarias empleadas para ello han sido varias bases cartográficas descargadas del Instituto Geográfico Nacional (SIOSE 2005 y 2011, CORINE LAND COVER 1990, 2000 y 2006; PNOA histórico 2004 y 2014; y las demarcaciones territoriales de CARTOCIUDAD 2011), así como los datos de los Censos de Población y Vivienda de 1991, 2001 y 2011 territorializados en base a los seccionados censales disponibles en el Instituto Nacional de Estadística. Para un mayor detalle sobre la metodología de adaptación cartográfica y estadística de las diferentes fuentes al objeto de esta investigación se remite al contenido completo de la investigación en su formato original.

\section{Marco conceptual. La reflexión en torno a lo urbano}

El carácter conceptual con que opera el urbanismo, el de las "unidades similares" -las delimitaciones administrativas municipales, regiones o países-, es un producto estructural de las prácticas sociales y las estrategias políticas; no ha de ser nunca entendido como una presunción. De esa forma, sería posible posicionar la investigación de la urbanización - «la destrucción creativa del espacio político-económico bajo el capitalismo"- en el epicentro de la teoría urbana. Es la nunca vista extensión de este proceso de destrucción creativa, más allá de la formación de una red mundial de ciudades globales o de la conceptualización de ella como una única megalópolis que abarca todo el planeta, lo que subraya la problemática contemporánea de la urbanización planetaria (BRENNER, 2013).

La urbanización se ha convertido en una de las narrativas dominantes a través de la cual interpretar la actual situación planetaria tanto en círculos académicos como en la esfera pública. Pese a que el viejo y anquilosado discurso de la dicotomía urbana-rural sigue aún vigente, la 
EL ÁREA URBANA FUNCIONAL DE MADRID (1991-2011).

METODOLOGÍA Y RESULTADOS DE UNA PROPUESTA DE DELIMITACIÓN Y CARACTERIZACIÓN MULTICRITERIO Territorios en Formación | 2017 | N11 | TRABAJOS FIN DE MÁSTER - Estudios Urbanos

realidad nos muestra, sin embargo, que el urbanismo como forma de vida ha traspasado esos límites, más allá de las megaciudades o el policentrismo de las nuevas concentraciones urbanas, se está produciendo una urbanización extensiva altamente extractiva -por sus consumos de suelo, materia y energía, y por la repercusión de sus redes, cuyo comportamiento metabólico es altamente insostenible, como resulta evidente en el caso de los transportes horizontales-. Los efectos urbanos persisten en un cada vez más heterogéneo paisaje socioespacial -cables submarinos; satélites artificiales de telecomunicaciones; la densificación del transporte horizontal aéreo, marítimo y terrestre; plataformas petrolíferas marinas; zonas de fracturación hidráulica; área inundadas por nuevas presas; desiertos intensivos en agricultura hidropónica; redes globales de turismo natural, cultural y de ocio; amplias áreas desertizadas; territorios de conflicto y desestabilización político-social motivadas por el control geoestratégico de recursos; incendios; deforestación; redes sociales digitales que generan movimientos transnacionales...-.

Según BRAUDEL (1984), "la ciudad como tal no existe más que por contraste con una vida inferior a la suya; es una regla que no admite excepciones, ningún privilegio puede sustituirla. No hay una ciudad, por pequeña que sea, que no tenga sus pueblos, su parte de vida rural anexionada, que no imponga a su "campiña" las comodidades de su mercado, el uso de sus tiendas, e incluso de sus distracciones. Para ser, necesita dominar un espacio, aunque sea minúsculo". ¿Ha dejado esto de ser cierto? Posiblemente no del todo, las ciudades como sumideros de flujos y oportunidades siguen estando ahí, pero tal vez no ya en oposición a un mundo rural sino en medio de un entramado de bordes urbanos. Para NEL.LO (1998), "la dualidad campo/ciudad estaba asociada, como toda formación espacial, a determinadas estructuras sociales y a coyunturas históricas concretas. Aquellas coyunturas han desaparecido y continuar utilizando esta dualidad como categoría de descripción y análisis es un anacronismo". Esto es así, tal y como postula DUPUY (1998), debido al "carácter absolutamente inédito del acceso generalizado a las redes urbanas. La electricidad, el gas, el automóvil, el teléfono, a los que hay que añadir la televisión -y ahora internet-, hicieron estallar los límites, en principio urbanos, de las redes técnicas, al acentuar la impresión de servicio para todos. La significación social del fenómeno es de un orden distinto al del suministro técnico de un simple servicio local. La significación territorial es, también, profundamente diferente, a causa de la generalización fuera del perímetro urbano tradicional. Las redes técnicas urbanas se han convertido en redes que participan de nuevas implicaciones sociales y de nuevas territorialidades". ROCA-CLADERA (2003) argumenta en consecuencia que "esta ausencia de frontera determina que el ecosistema urbano tan solo pueda ser definido, delimitado, en función de un gradiente de urbanización. Gradiente de intensidad de la edificación, de extensión e influjo de las infraestructuras de comunicación; gradiente de actividad y estructura económica, de movilidad de mercancías y de personas; gradiente, en suma, de articulación del medio, así como de impacto ecológico".

Por otro lado, se están cristalizando nuevos vectores de lucha social urbana. La producción del espacio responde, cada vez más y exclusivamente, a lógicas de producción capitalista y ello ha generado la reivindicación del derecho a la ciudad, la búsqueda del espacio social perdido. La desigualdad constituye, ahora más que nunca, un acercamiento vital a las conceptualizaciones del sistema urbano mundial. Esta desigualdad es evidente entre unidades territoriales estatales, pero tampoco hemos de olvidar las tremendas disparidades de distribución de renta en el interior de los distintos países. Existen búnkeres del lujo en los países menos ricos y amplias bolsas de exclusión social y pauperización en los autodenominados "desarrollados". Sin negar la importancia radical de la desigualdad interterritorial, nosotros como urbanistas tenemos la obligación de conceptualizar nuestras ciudades como lugares frontera. En dicha conceptualización, una frontera sería aquel 
lugar donde dos mundos se tocan sin una estipulación prefijada de las reglas para tal encuentro. En ese sentido las grandes áreas urbanas funcionales son lugares paradigmáticos donde la opulencia de las élites y la vulnerabilidad material de los grupos más desfavorecidos se encuentran en continua pugna por la consecución de sus muy diversos intereses. Son nuestras ciudades donde se libran las batallas cotidianas por una sociedad más igualitaria contra el rampante proceso de aumento de la desigualdad. Para SASSEN (2014), "la ciudad es hoy un espacio de combate abierto", pero ¿cuándo ha dejado esto de ser así? Como MUMFORD (1965) enunció hace ya más de medio siglo: "más que una masa de estructuras, la ciudad es un complejo de funciones interrelacionadas y en constante interacción; no sólo una concentración de poder sino una polarización de la cultura".

El concepto de urbanización requiere de una sistemática reinvención. Hay que escapar de las aproximaciones tradicionales que ligaban el proceso urbano al crecimiento de determinados tipos de asentamientos consideradas como unidades discretas, contenidas y embebidas en un amplio paisaje sin urbanizar. Ya en 1990, FISHMAN se atrevió a salirse de lo convencional y abrir agujeros a lo preconcebido al enunciar que "las "personas" crean sus propias "ciudades" a partir de los destinos que realizan... La estructura creada por esos destinos representa "la ciudad" para cada persona concreta. ...La nueva ciudad es una ciudad a la carta. Está compuesta por tres tipos de redes superpuestas ...La red de los hogares se compone de los lugares que forman parte de la vida familiar y personal ...La red de consumo comprende los centros comerciales, hipermercados, lugares de ocio y la segunda residencia ...La red de producción incluye los lugares de empleos y los ofertantes que esas empresas relacionan ...Cada una de esas redes tiene su propia lógica espacial".

\section{Marco de análisis y delimitación del área urbana funcional de Madrid}

La necesidad de escapar de las constricciones dadas por delimitaciones urbano-administrativas apriorísticas y la intención de apostar por análisis centrados en esencias constitutivas que focalicen sobre los procesos urbanos de contexto, más allá de las esencias nominales que tradicionalmente han sido definidas por tipologías de asentamiento en base al tamaño poblacional o la densidad bruta territorial, suscitan la base de esta investigación. Además, como ya se ha enunciado, ante la ausencia de una frontera delimitable de lo urbano, esta realidad social tan solo puede ser definida en función de un gradiente de urbanización, de intensidad de la edificación, de extensión e influjo de las infraestructuras de comunicación, de actividad y estructura económica; en suma, de articulación del medio territorial, así como de impacto ecológico.

Con el objetivo de enunciar procesos constitutivos sólidos en la realidad urbana española este texto se asienta en los trabajos desarrollados por el MINISTERIO DE FOMENTO (2015) para la creación del Atlas estadístico de las áreas urbanas y EUROSTAT (2016), en colaboración con el Instituto Nacional de Estadística, para la gestación del proyecto Urban Audit y su delimitación de Áreas Urbanas Funcionales. A partir de ellos se han catalogado los siguientes procesos:

- Una realidad "sin concentración de servicios", esto es, el proceso que sufre la mayor parte del amplio territorio peninsular. El otrora medio rural, está sufriendo una pérdida de su peso demográfico en el conjunto de España cada vez mayor. Se trataría en realidad de unos bordes urbanos cuya población se mantiene gracias a la carga social que asume su "generación soporte" y a políticas de cohesión territorial como la PAC o el PER.

- Una "concentración de servicios a escala comarcal». Este tipo de procesos aparecen en algunos nodos difusos del territorio de las zonas anteriores, que por su centralidad están asumiendo un rol protagonista en los procesos de comarcalización y gestación de 
EL ÁREA URBANA FUNCIONAL DE MADRID (1991-2011).

METODOLOGÍA Y RESULTADOS DE UNA PROPUESTA DE DELIMITACIÓN Y CARACTERIZACIÓN MULTICRITERIO

Territorios en Formación | 2017 | N11 | TRABAJOS FIN DE MÁSTER - Estudios Urbanos

mancomunidades para la prestación de servicios en un marco cada vez más insostenible de gestión pública.

- Una "concentración de servicios a escala regional y/o provincial" donde no llegan a darse procesos perceptibles de integración urbana más allá de los límites del territorio municipal. Estas entidades estarían aún en un primer proceso de concentración pronunciada, pero sin haber generado con ello una extensión-gradiente de los procesos que definen su urbanización.

- Por último, la generación de "áreas urbanas funcionales", denominadas por su núcleo central municipal o conurbación, cuya zona de influencia engloba un amplio territorio circundante. Aquí sí encontraríamos la dialéctica entrelazada entre concentración y extensión, pudiéndose definir el enunciado gradiente.

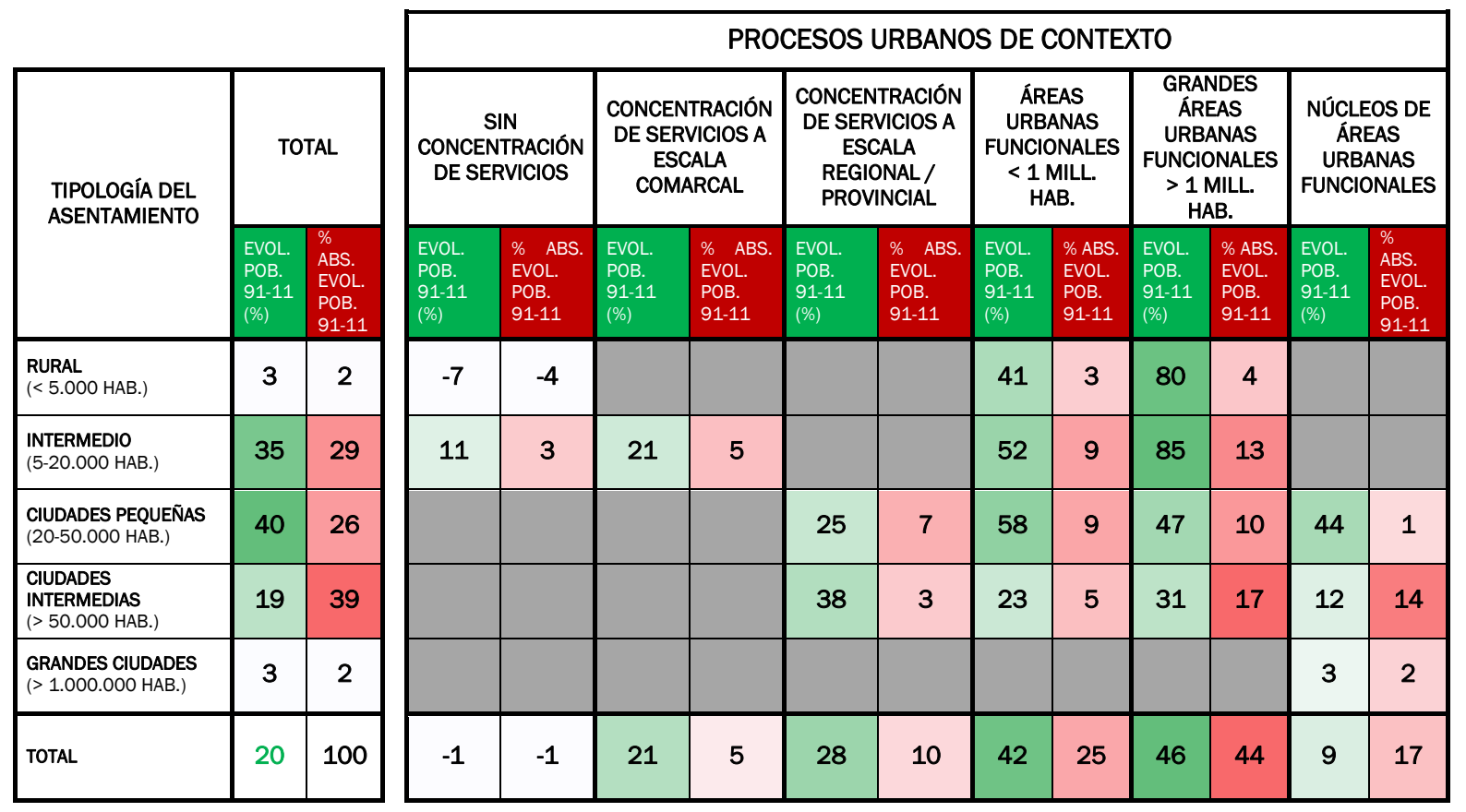

Tabla 1: Evolución relativa -verde- y reparto porcentual del incremento demográfico absoluto del estado español -rojo- entre 1991 y 2011 (Fuente: INE, 1991 y 2011b)

Una mirada a las dinámicas que los caracterizan, como es la evolución demográfica recogida en la Tabla 1, aporta una visión descriptiva de la idoneidad del enfoque. El análisis de sus datos aporta tres reflexiones principales:

- La importancia de los procesos contextuales como definidores de las dinámicas que enfrenta lo urbano. La convencional clasificación tipológica en base al tamaño poblacional de los asentamientos esconde en realidad una gran diversidad de procesos en su seno. Como se observa en la tabla anterior, nada tienen que ver los asentamientos "rurales" caracterizados por la inexistencia de una concentración de servicios, que acumulan una pérdida demográfica de hasta el 7\%, y los contextualizados en procesos de áreas funcionales, en especial las más grandes, que acumulan un crecimiento poblacional de más del $80 \%$.

- La sustantiva relevancia de los procesos de conformación de áreas urbanas funcionales en el territorio español, y no precisamente protagonizado por sus centros. Las áreas funcionales en su conjunto suponen más del 70\% de la población total española, pero, lo más importante, han acumulado más del $85 \%$ del crecimiento demográfico absoluto de las dos últimas décadas. 
- Las periferias de las áreas funcionales cuadriplican el crecimiento demográfico experimentado por sus centros, tanto en términos relativos como absolutos. Esta constatación nos advierte de la importancia de la urbanización extensiva en las actuales dinámicas urbanas. Los municipios supuestamente "no urbanos" en su seno, que solo suponían el $8 \%$ de la población española en 1991, han acumulado casi el 30\% del aumento demográfico de las últimas dos décadas con lo que en 2011 han pasado a suponer más del 12\%.

Llegados a este punto, convencidos de la idoneidad de este enfoque para abordar lo urbano, no hemos indagado aún en la metodología para la delimitación de áreas urbanas funcionales: problema central de esta investigación que afronta la caracterización de una en concreto, la madrileña. ¿Cómo delimitarla? Parece que la integración del mercado laboral, que toman como base tanto el MINISTERIO DE FOMENTO (2015) como EUROSTAT (2016), es un indicador lógico de los procesos de interdependencia funcional de un territorio urbano. Para abordar esta cuestión se han examinado seis propuestas (ver Fig. 2) y todas ellas lo emplean en sus metodologías como indicador principal para establecer la delimitación del área funcional.

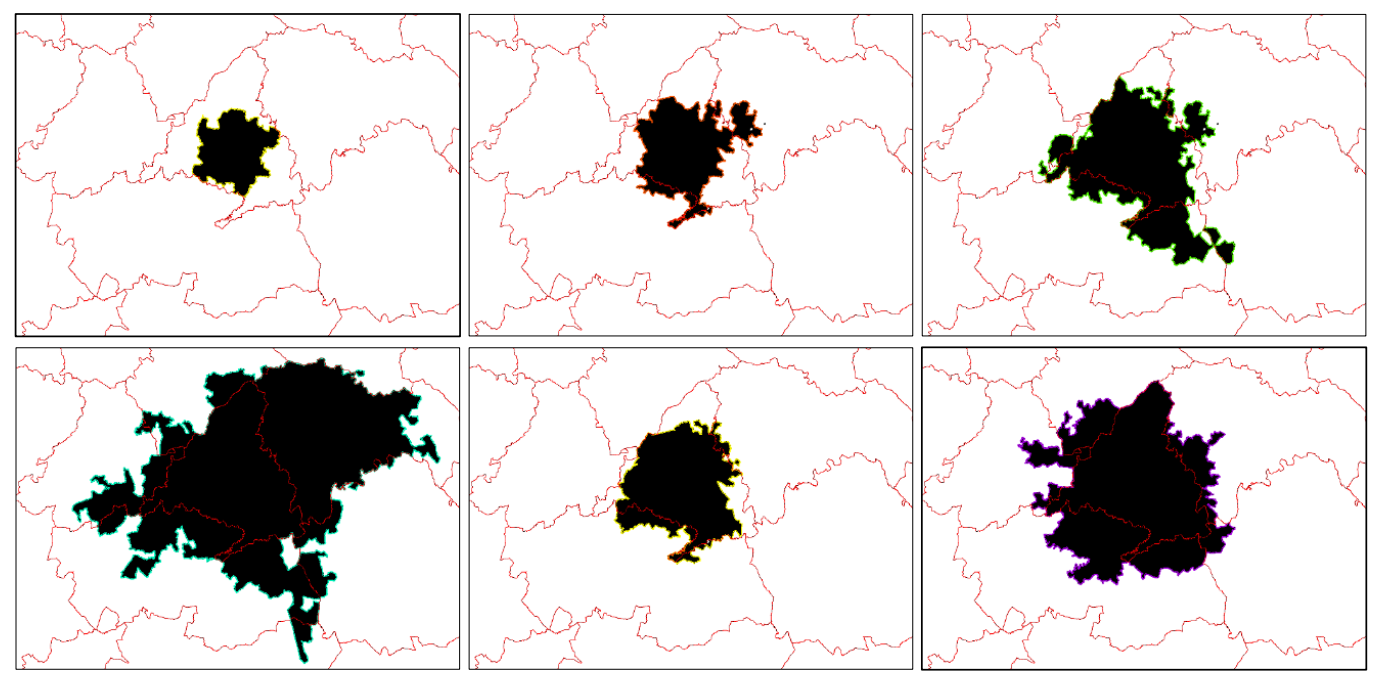

Figura 2: Propuestas de delimitación del A.U.F.M. Desde arriba y de izquierda a derecha: INE (2001a), RUIZ (2001), FERIA (2008), BURS (2009), INE (2011a), AYTO. DE MADRID (2014)

La integración del mercado laboral de un determinado territorio es cuantificable a través de lo que en inglés se conoce como "commuting". El término correspondiente en español sería el de "movimiento o migración pendular", es decir, el desplazamiento desde el lugar de residencia al lugar de trabajo, estudio o abastecimiento por periodos diarios, ida y vuelta. Siguiendo con esta conceptualización, un área urbana funcional estaría constituida por dos zonas diferenciadas y conectadas en red: un centro o núcleo que acumularía principalmente la actividad laboral, pedagógica, mercantil, cultural... y el área aledaña que conforma su entorno funcional por la atracción e influencia que generan dichas actividades. De este modo, si de la integración del mercado laboral se trata, el indicador medirá el número de desplazamientos al trabajo desde un entorno periférico hacia su núcleo de influencia, el lugar en que se desarrolla la actividad. Cinco de estas metodologías apuestan por restringir el núcleo del área funcional al municipio de Madrid; delimitando para el resto de entidades municipales del entorno la pertenencia o no al área, sin grises intermedios. Desde nuestro enfoque, sin embargo, entendemos necesario incluir un gradiente de intensidad a esta delimitación, así como, no restringir necesariamente el núcleo funcional a un único municipio. Y estas dos características se encuentran sólo en la propuesta del AYUNTAMIENTO DE MADRID (2014). 
EL ÁREA URBANA FUNCIONAL DE MADRID (1991-2011).

METODOLOGÍA Y RESULTADOS DE UNA PROPUESTA DE DELIMITACIÓN Y CARACTERIZACIÓN MULTICRITERIO Territorios en Formación | 2017 | N11 | TRABAJOS FIN DE MÁSTER - Estudios Urbanos

Su metodología se basa en la determinación de un "índice sintético de metropolización" que recoge once variables y alcanza su mayor intensidad en el área central que está compuesta por quince municipios: además de Madrid, la mayoría se localizan en el arco sur (Alcorcón, Getafe, Fuenlabrada, Leganés, Parla y Móstoles), seguidos por otros municipios vecinos a la capital por el Corredor del Henares (Coslada, San Fernando de Henares y Torrejón de Ardoz), el eje de la A-6 (Pozuelo de Alarcón, Las Rozas y Majadahonda) y el acceso de la A-1 (Alcobendas y San Sebastián de los Reyes). Se trata del área pionera en la expansión metropolitana, en adelante, "área urbana consolidada", la más vertebrada por la red de comunicaciones, la que alcanza las mayores densidades de población y actividades económicas, y en la que con más frecuencia aparecen continuos urbanos que transcienden los límites administrativos (como son los ejemplos de Las Tablas-Alcobendas-San Sebastián de los Reyes, Aravaca-Pozuelo de Alarcón, San Blas-Coslada-San Fernando de Henares y Villaverde-Getafe-Leganés).

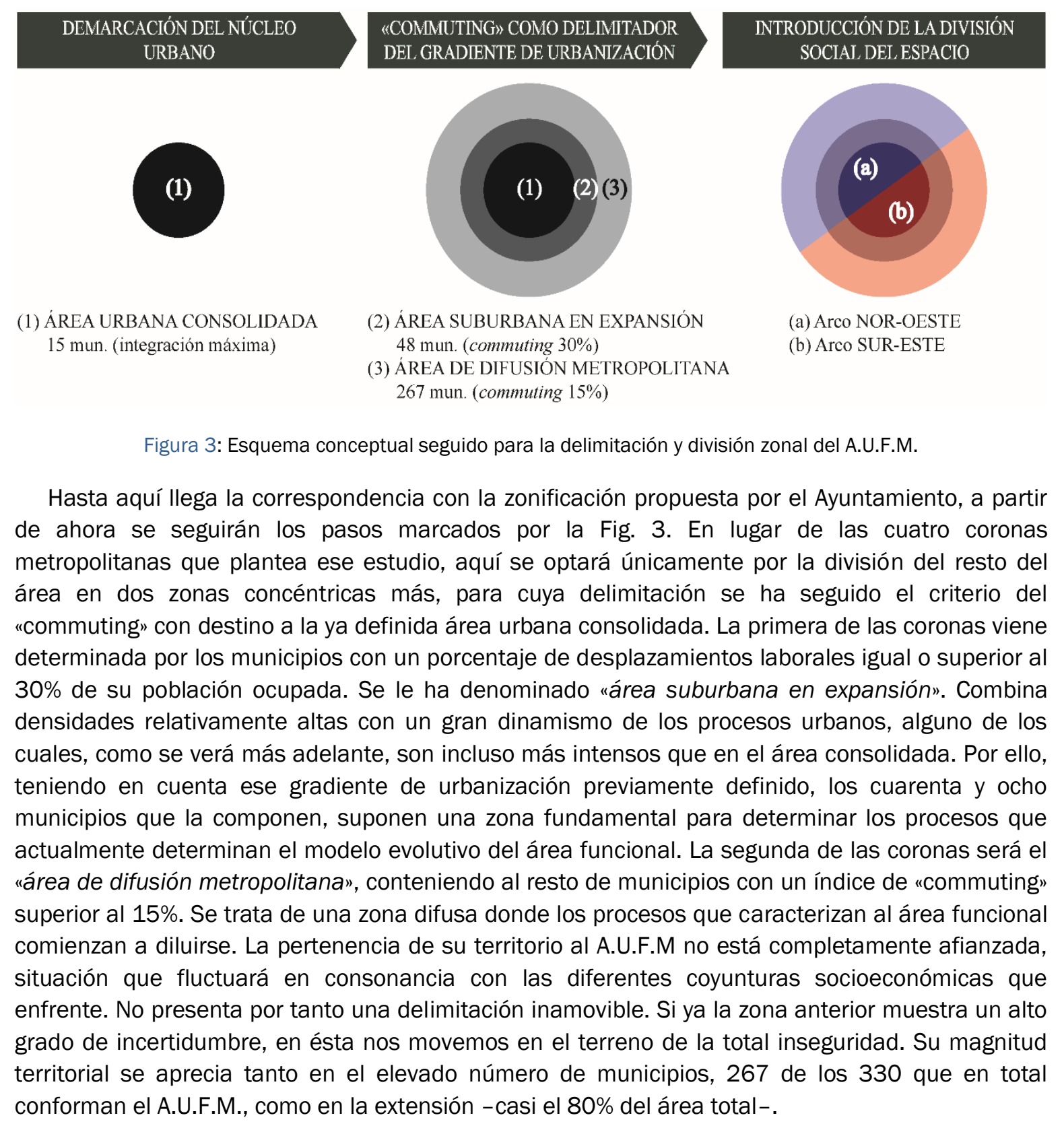


Mientras la zona consolidada alberga a casi el $70 \%$ de la población, el resto se reparte a partes casi iguales entre las otras dos zonas concéntricas. Respecto a la evolución demográfica (ver Tabla 2) se observa que el área suburbana ha duplicado con creces su peso poblacional durante las dos décadas de estudio, siendo sus municipios más pequeños los que concentran los mayores crecimientos relativos, llegando a cuadriplicar su población. En conjunto, esta zona ha acumulado casi el $40 \%$ del crecimiento absoluto. El área consolidada pierde peso relativo ya que a pesar de haber acumulado el 35\% del crecimiento absoluto, su incremento relativo no llega al 15\% mientras que para el conjunto supera el 30\%. Por último, el área de difusión sí que aumenta su peso poblacional con un incremento relativo superior al $80 \%$. En esta zona también se aprecia el gran dinamismo de los núcleos de menor entidad, no solo por la atracción que ejerce la capital sino por la existencia de dinámicas propias de suburbanización en torno a entidades intermedias como Toledo, Segovia, Guadalajara o Aranjuez (ver Fig. 4).

\begin{tabular}{|c|c|c|c|c|c|c|c|c|}
\hline \multirow{3}{*}{$\begin{array}{l}\text { TIPOLOGÍA DE } \\
\text { ASENTAMIENTOS }\end{array}$} & & & \multicolumn{6}{|c|}{ GRADIENTE DE URBANIZACIÓN DEL A.U.F.M } \\
\hline & \multicolumn{2}{|c|}{ TOTAL } & \multicolumn{2}{|c|}{$\begin{array}{l}\text { ÁREA URBANA } \\
\text { CONSOLIDADA }\end{array}$} & \multicolumn{2}{|c|}{$\begin{array}{c}\text { ÁREA SUBURBANA EN } \\
\text { EXPANSIÓN }\end{array}$} & \multicolumn{2}{|c|}{$\begin{array}{c}\text { ÁREA DE DIFUSIÓN } \\
\text { METROPOLITANA }\end{array}$} \\
\hline & $\begin{array}{c}\text { EVOL. POB. } \\
91-11 \\
(\%)\end{array}$ & $\begin{array}{c}\text { \% EVOL. ABS. } \\
\text { POB. } \\
91-11\end{array}$ & $\begin{array}{l}\text { EVOL. POB. } \\
91-11(\%)\end{array}$ & $\begin{array}{c}\text { \% EVOL. ABS. } \\
\text { POB. } \\
91-11\end{array}$ & $\begin{array}{l}\text { EVOL. POB. } \\
\text { 91-11 (\%) }\end{array}$ & $\begin{array}{c}\text { \% EVOL. ABS. } \\
\text { POB. } \\
91-11\end{array}$ & $\begin{array}{c}\text { EVOL. } \\
\text { POB. } \\
91-11(\%)\end{array}$ & $\begin{array}{c}\text { \% EVOL. ABS. } \\
\text { POB. } \\
91-11\end{array}$ \\
\hline $\begin{array}{l}\text { RURAL } \\
(<5.000 \text { HAB. })\end{array}$ & 105,3 & 10,8 & & & 310,8 & 0,7 & 101,0 & 10,2 \\
\hline $\begin{array}{l}\text { INTERMEDIO } \\
(5-20.000 \text { HAB. })\end{array}$ & 184,6 & 23,7 & & & 266,0 & 11,3 & 144,2 & 12,3 \\
\hline $\begin{array}{l}\text { CIUDADES PEQUEÑAS } \\
(20-50.000 \text { HAB. })\end{array}$ & 140,5 & 15,3 & 60,7 & 0,8 & 152,2 & 14,5 & & \\
\hline $\begin{array}{l}\text { CIUDADES INTERMEDIAS } \\
(>50.000 \text { HAB.) }\end{array}$ & 40,8 & 39,8 & 33,9 & 23,6 & 87,5 & 11,8 & 30,3 & 4,3 \\
\hline $\begin{array}{l}\text { GRANDES CIUDADES } \\
\text { (> 1.000.000 HAB.) }\end{array}$ & 6,2 & 10,4 & 6,2 & 10,4 & & & & \\
\hline TOTAL & 33,6 & 100 & 14,7 & 34,9 & 139,3 & 38,3 & 81,4 & 26,9 \\
\hline
\end{tabular}

Tabla 2: Evolución demográfica relativa -verde- y reparto porcentual del incremento demográfico absoluto del A.U.F.M -rojo- entre 1991 y 2011 (Fuente: INE, 1991 y 2011b)
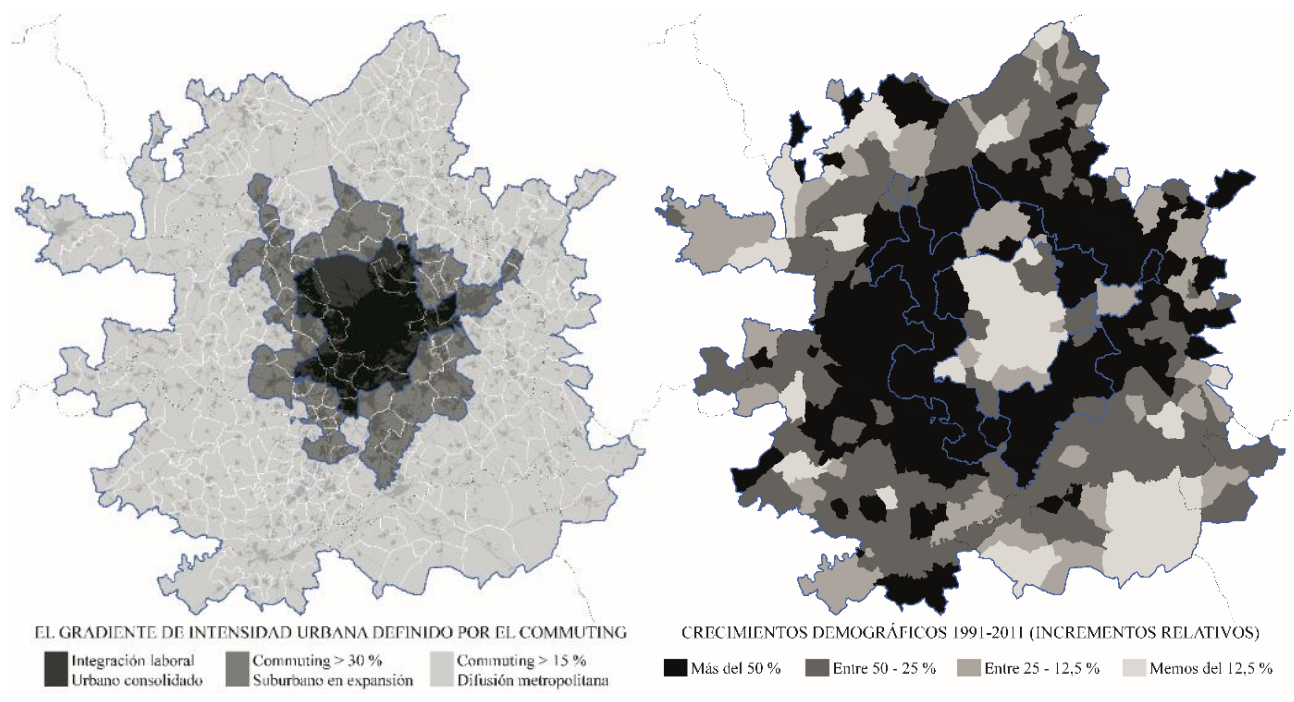

Figura 4: Gradiente de intensidad de los procesos de urbanización y crecimiento relativo entre 1991 y 2011 de los municipios pertenecientes al A.U.F.M (Fuente: INE, 1991 y 2011b)

Por otro lado, las transformaciones socioeconómicas ocurridas en los últimos años han repercutido en el desarrollo de una serie de fenómenos relacionados con la reestructuración del espacio social madrileño. La revalorización de lo complejo y lo diverso en tanto "atractores" de la innovación y la creatividad está cambiando por completo el mapa conceptual del espacio social en 
gran parte de las generaciones más jóvenes. Junto a este "acicalamiento" superficial, no solo del centro turístico sino del empresarial, emanado de la imagen de la ciudad global como paradigma económico y social; se ha producido un incremento en los procesos de desigualdad en términos de polarización social con unas clases altas más numerosas y más distanciadas de las clases bajas que perdían poder adquisitivo e incrementaban también su volumen (LEAL, 2008). Madrid "ha dejado de ser la ciudad de las administraciones públicas, rodeada por un gran cinturón industrial, para ser cada vez más un centro regional de negociación e intermediación financiera, sede estratégica de grandes corporaciones empresariales" (OBSERVATORIO METROPOLITANO, 2007). Ese nudo industrial fue el que acogió a las clases trabajadoras tras el éxodo rural: los accesos desde Extremadura y Andalucía, y el eje industrial del Corredor del Henares. Dicha línea, la delimitada por la A-5, el arco sureste de la M-30 y la -A-2, suponía -y supone- el eje tradicional de división de la renta en el espacio madrileño. ¿Sigue vigente dicha dicotomía socioespacial -noroeste/sureste- y es extrapolable al conjunto del área funcional? Por un lado, las dinámicas de crecimiento del área suburbana han hecho que municipios como Rivas-Vaciamadrid o Arroyomolinos se posicionen como lugares elegibles para una parte de la población joven de renta media-alta; por otro, existen zonas en el arco noroeste como parte del distrito de Tetuán o Embajadores que tradicionalmente han acogido a rentas medias-bajas. Sin embargo, este texto partió de la hipótesis de pervivencia de dicho eje como caracterizador fundamental de la división social del espacio madrileño. De esta forma, se presupone aún vigente una cierta polarización entre los arcos noroeste y sureste, potencialmente extrapolable a la totalidad del área funcional. En consonancia, el último paso para la zonificación de la delimitación funcional propuesta será la fracturación de las tres zonas concéntricas anteriores por el eje mencionado. Con ello, se obtendrán finalmente seis áreas para el estudio y caracterización del A.U.F.M. (ver Fig. 5).

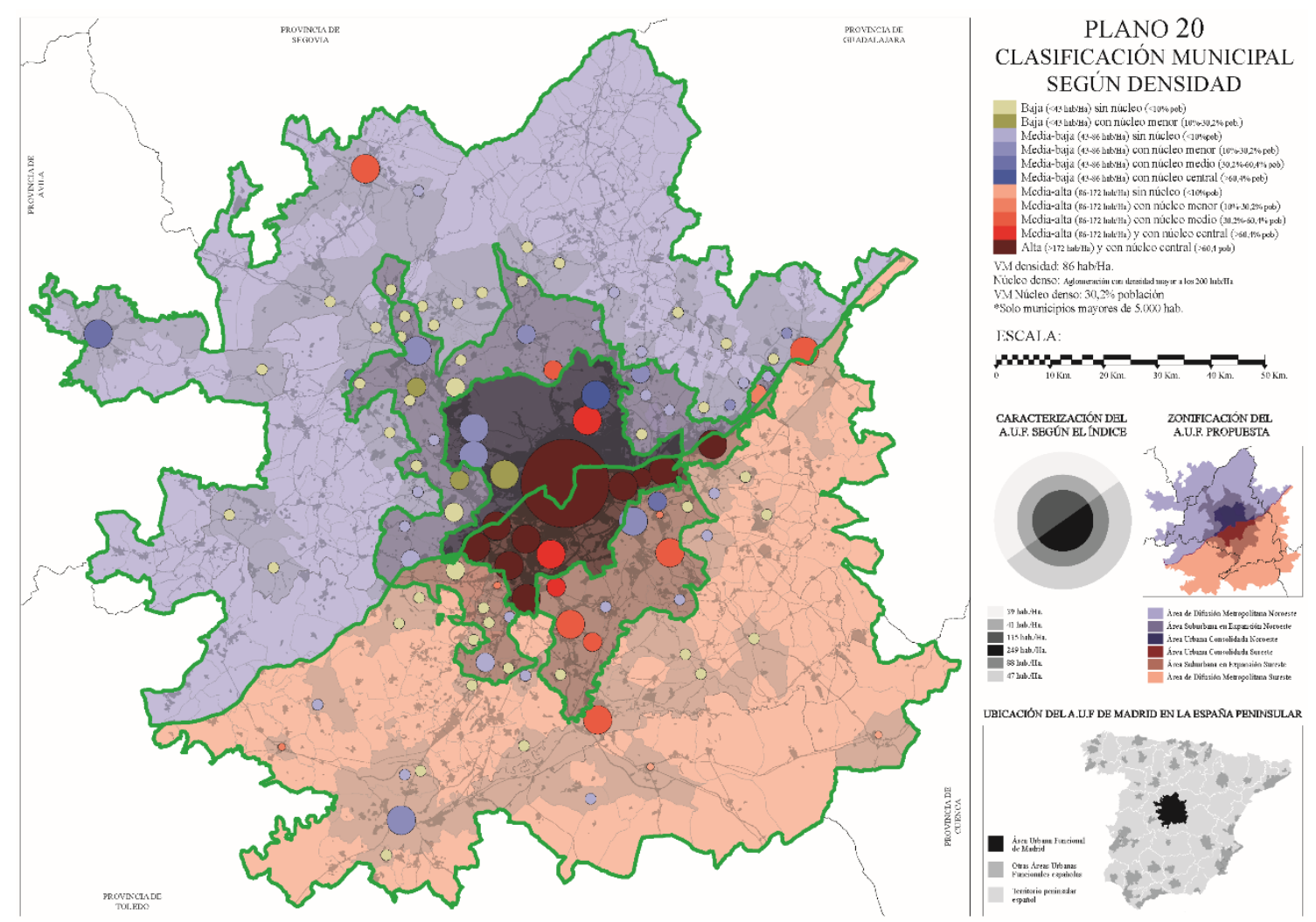

Figura 5: Sistema urbano y división zonal propuesta para el A.U.F.M, con la superposición del gradiente urbano y la fractura socioespacial definida por la A-5, el arco sureste de la M-30 y la A-2. 


\section{Resultados. La caracterización del área urbana funcional de Madrid}

A partir de este punto se enunciarán únicamente los principales resultados obtenidos por la investigación. El cometido principal de esta comunicación es transmitir el enfoque metodológico mantenido. Para un mayor acercamiento al contenido detallado se remite al trabajo original. En él se establecen hasta treinta índices sintéticos de caracterización de las seis zonas propuestas del A.U.F.M. y se anexan veintiséis planos, la mayoría de los cuales ofrece datos desagregados a nivel censal. Los índices muestran tanto variables espaciales como sociodemográficas. En este artículo nos centraremos en las primeras.

\subsection{Concentración y urbanización extensiva}

La urbanización del A.U.F.M. contiene los dos momentos dialécticamente entrelazados ya enunciados: concentración y extensión. No hemos de olvidar que ello comporta la dependencia funcional de la mayoría de sus puntos. En los primeros tres índices estudiados -respecto a la artificialización del suelo-, la constatación del gradiente de urbanización es clara, como también lo son las diferencias entre el arco noroeste y sureste. Estos índices miden el porcentaje total de suelo cubierto por superficies artificiales -tejido urbano continuo y discontinuo, áreas productivas, equipamientos, infraestructuras y zonas en construcción- a partir de los resultados del proyecto de la Agencia Europea del Medio Ambiente, Corine Land Cover, realizado sucesivamente en 1990, 2000 y 2006 (IGN).
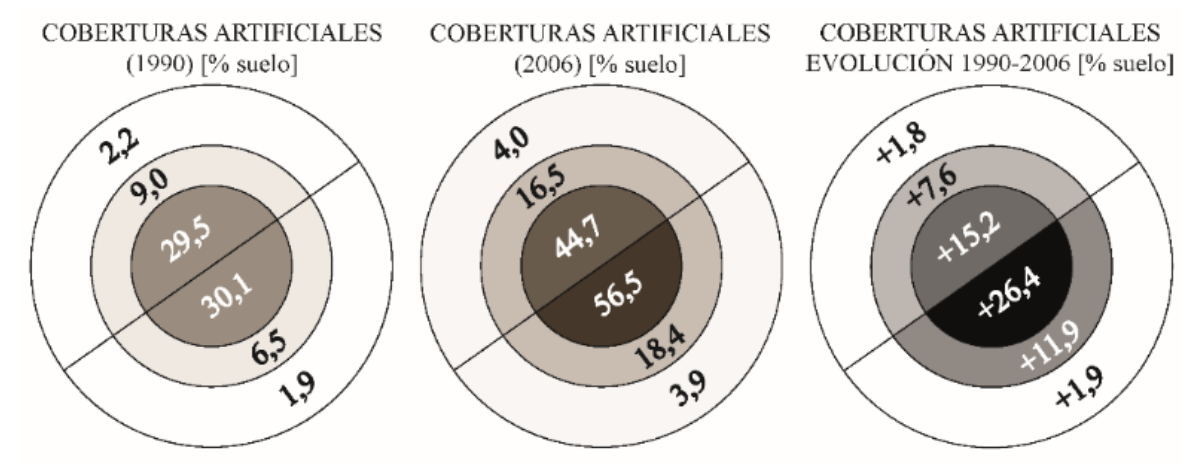

Figura 6: Índices sintéticos que miden la transformación de las coberturas en el A.U.F.M. (IGN, 1990 y 2006)

Las áreas del sur han sufrido una mayor artificialización de sus suelos (ver Fig. 6), pero como se observa en el índice de 1990 esta no era la situación inicial para las áreas de expansión y difusión, que estaban más trasformadas en el arco noroeste. De hecho, desde dicho año al 2000 la intensidad del proceso continuó siendo mayor en este arco; no ha sido hasta los últimos seis años del periodo cuando se ha dado la vuelta a la comparativa. De esta forma, es lógico pensar que el estallido de la burbuja ha producido mayores efectos en estas zonas caracterizadas por un boom de transformación más tardío, que ya había perdido intensidad en el arco noroeste. Ello ha dejado una gran cantidad de suelo urbanizado en las zonas sureste en expansión y de difusión que, sin embargo, aún está por desarrollar edificatoriamente: los cadáveres de la burbuja. En cualquier caso, de repetirse el ritmo transformador de este periodo, en solo tres siglos se colmataría completamente el área funcional y solo bastarían cuarenta años para "completar" el área consolidada del sureste. 
EL ÁREA URBANA FUNCIONAL DE MADRID (1991-2011).

METODOLOGÍA Y RESULTADOS DE UNA PROPUESTA DE DELIMITACIÓN Y CARACTERIZACIÓN MULTICRITERIO Territorios en Formación | 2017 | N11 | TRABAJOS FIN DE MÁSTER - Estudios Urbanos
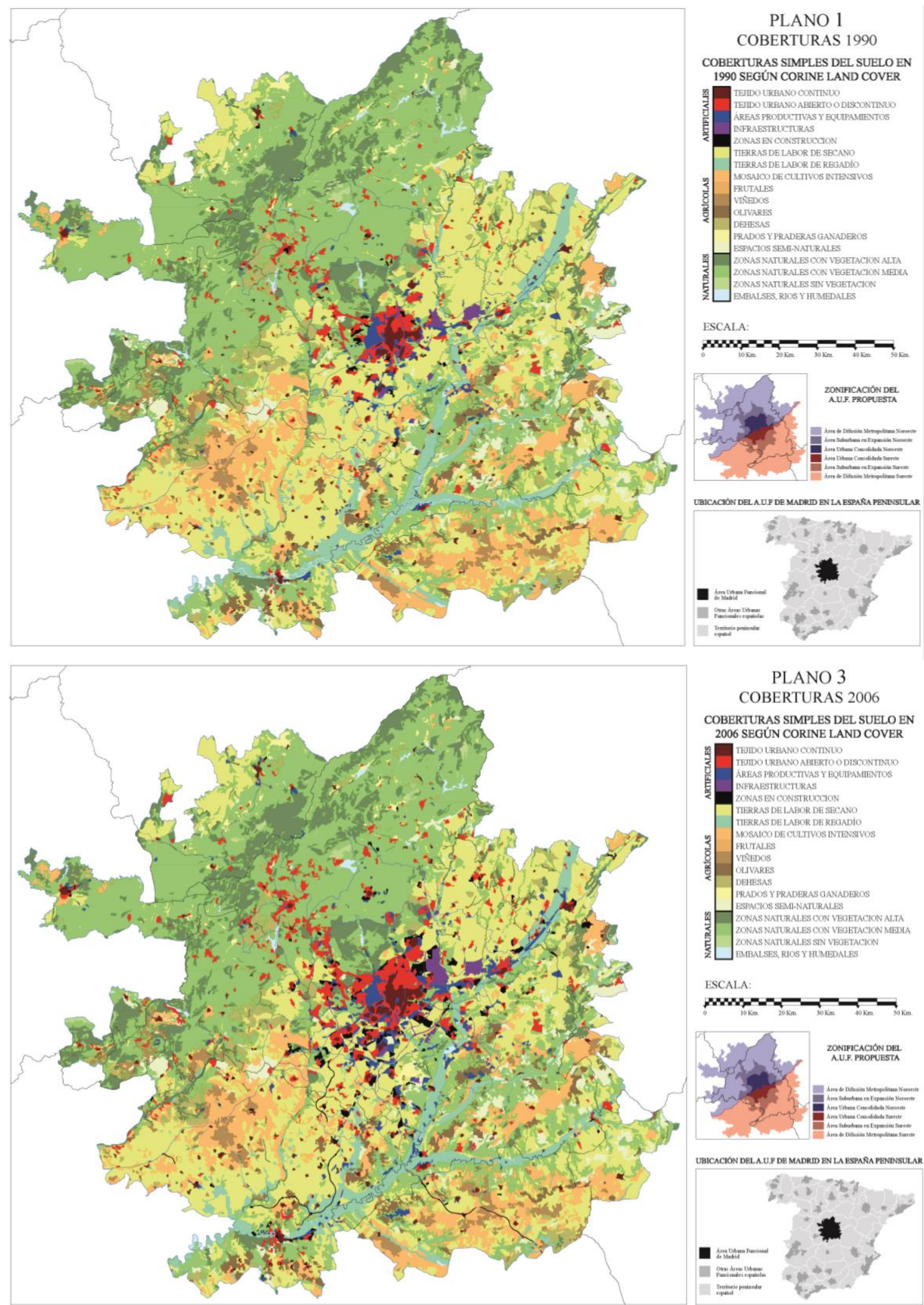

PLANO 3

COBERTURAS 2006

COBERTURAS SIMPLES DEL SUELO EN 2006 SEGÚN CORINE LAND COVER

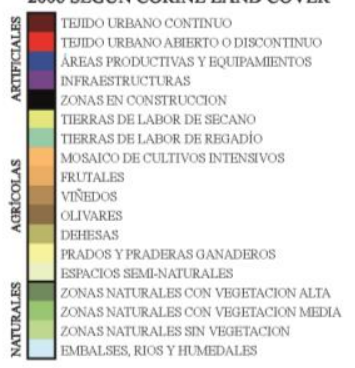

ESCALA:
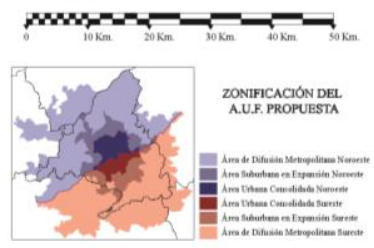

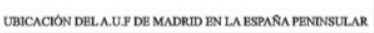

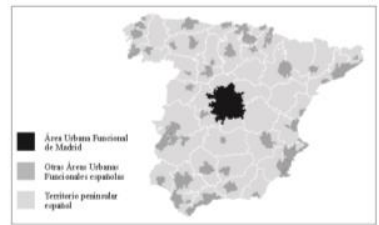

Figura 7: Evolución de las coberturas del suelo entre 1990 y 2006 en el A.U.F.M. (IGN, 1990 y 2006) 

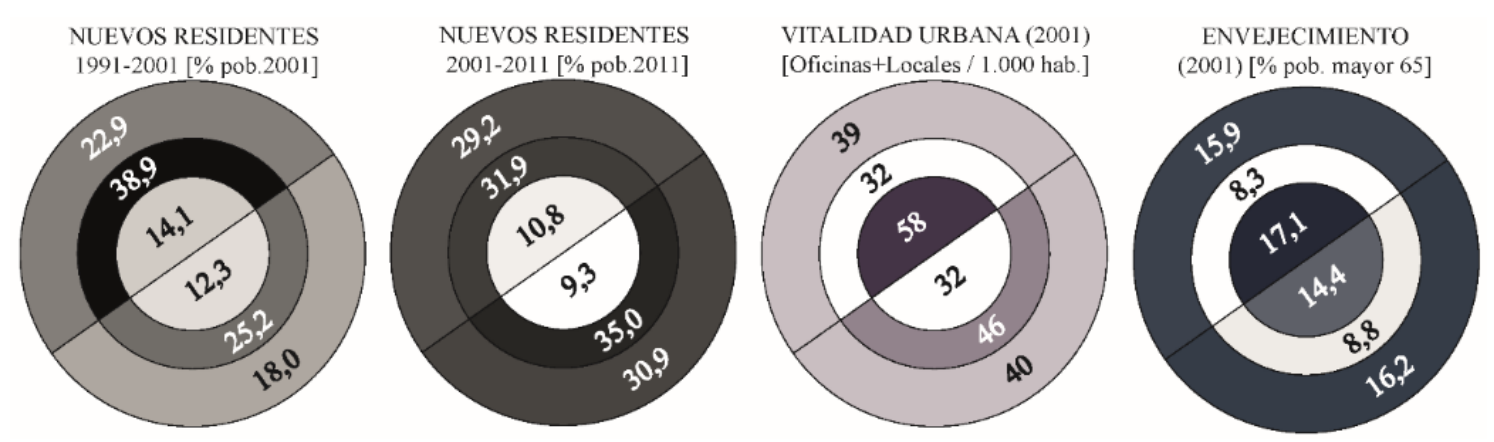

Figura 8: Índices sintéticos que miden la capacidad de atracción, la vitalidad urbana y el envejecimiento en el A.U.F.M (INE, 2001b y 2011 b)

En oposición a esa transformación del suelo que habla de una concentración nuclear, se observa, por el contrario, que la mayor capacidad atractiva -de familias jóvenes, en su mayoríaestá presente en la periferia del A.U.F.M. (ver Fig. 8). Dos conclusiones se obtienen a este respecto. Uno, se constata la diferencia de ritmos entre el arco noroeste y sureste -mientras que el primero fue más atractivo durante el periodo de 1991 a 2001, el segundo tomó las riendas en el segundo periodo, 2001-2011-. Dos, se observa claramente la intensificación del proceso de urbanización extensiva: mientras que en el primer periodo fue el $25 \%$ de la nueva población la que apostó por ubicarse en un radio superior a los $25 \mathrm{~km}$ de distancia al centro funcional, en el segundo periodo esta cifra subió hasta superar el $40 \%$. Todo ello, en contraposición a un índice de vitalidad que nos indica como el mayor dinamismo se encuentra en el área consolidada noroeste, mientras que el sureste consolidado y el noroeste en expansión son las dos zonas más dependientes.

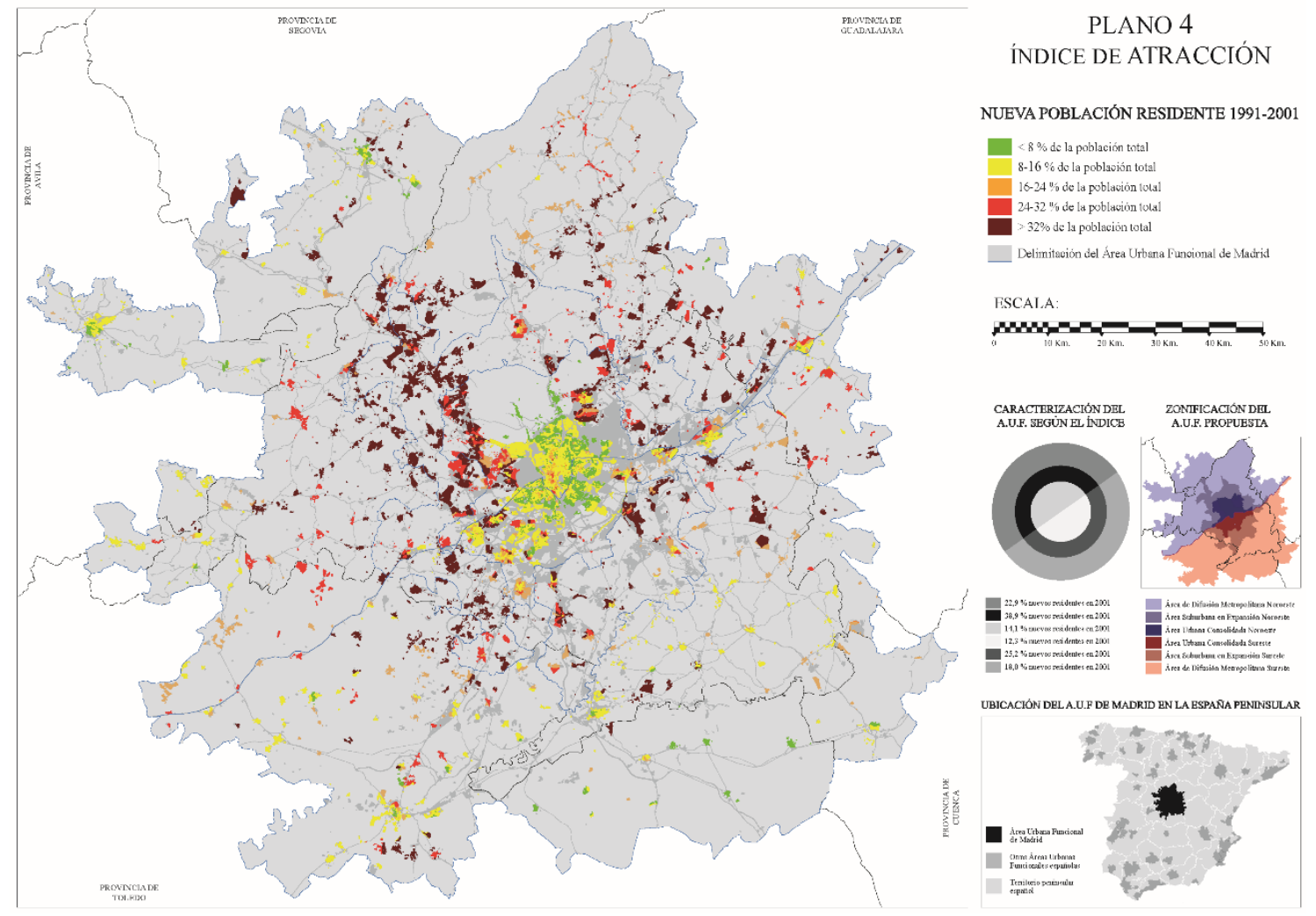

Figura 9: Los índices de atracción demográfica muestran la realidad de la urbanización extensiva (INE, 2001b) 
EL ÁREA URBANA FUNCIONAL DE MADRID (1991-2011).

METODOLOGÍA Y RESULTADOS DE UNA PROPUESTA DE DELIMITACIÓN Y CARACTERIZACIÓN MULTICRITERIO Territorios en Formación | 2017 | N11 | TRABAJOS FIN DE MÁSTER - Estudios Urbanos

\subsection{La movilidad en el modelo de ciudad}

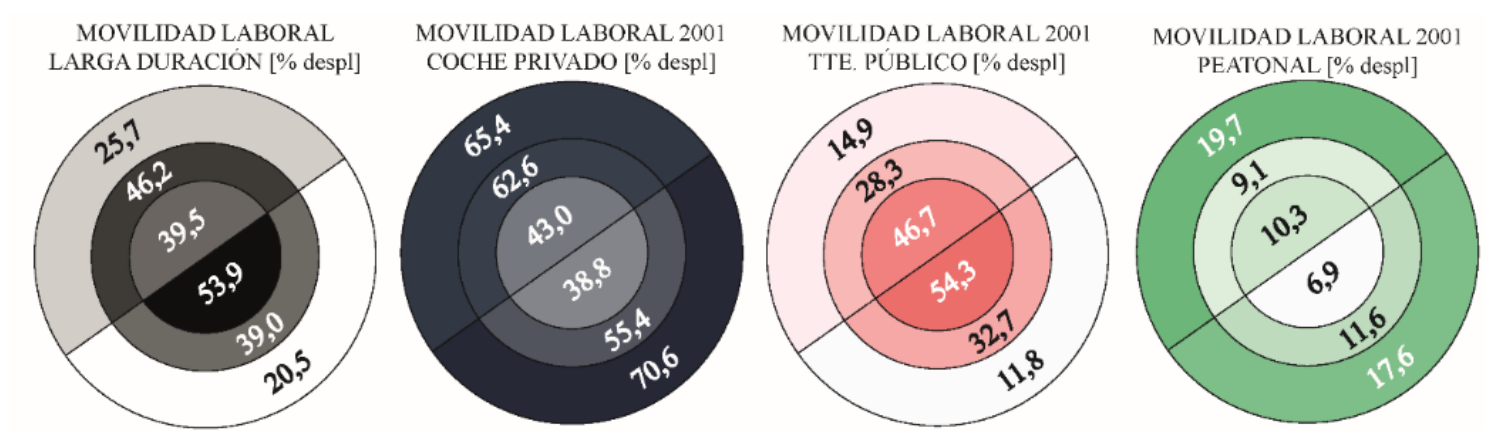

Figura 10: Índices sintéticos de movilidad (INE, 2001b)

Resulta curioso ver como la zona que alberga al $40 \%$ de la población del A.U.F.M, la consolidada sureste, es aquella donde un mayor porcentaje de trabajadores emplea más de media hora en ir a trabajar -aquí denominada movilidad laboral de larga duración-. Además, es la zona donde más se emplea el transporte público, hecho que no deja en buen lugar su eficacia. En contraposición, la zona noroeste en expansión, la segunda con un mayor índice de movilidad laboral de larga duración, apuesta por un modelo intensivo en el uso del transporte privado (ver Fig. 20). Hecho preocupante por tratarse de la zona con mayor tasa de actividad y menos población envejecida.

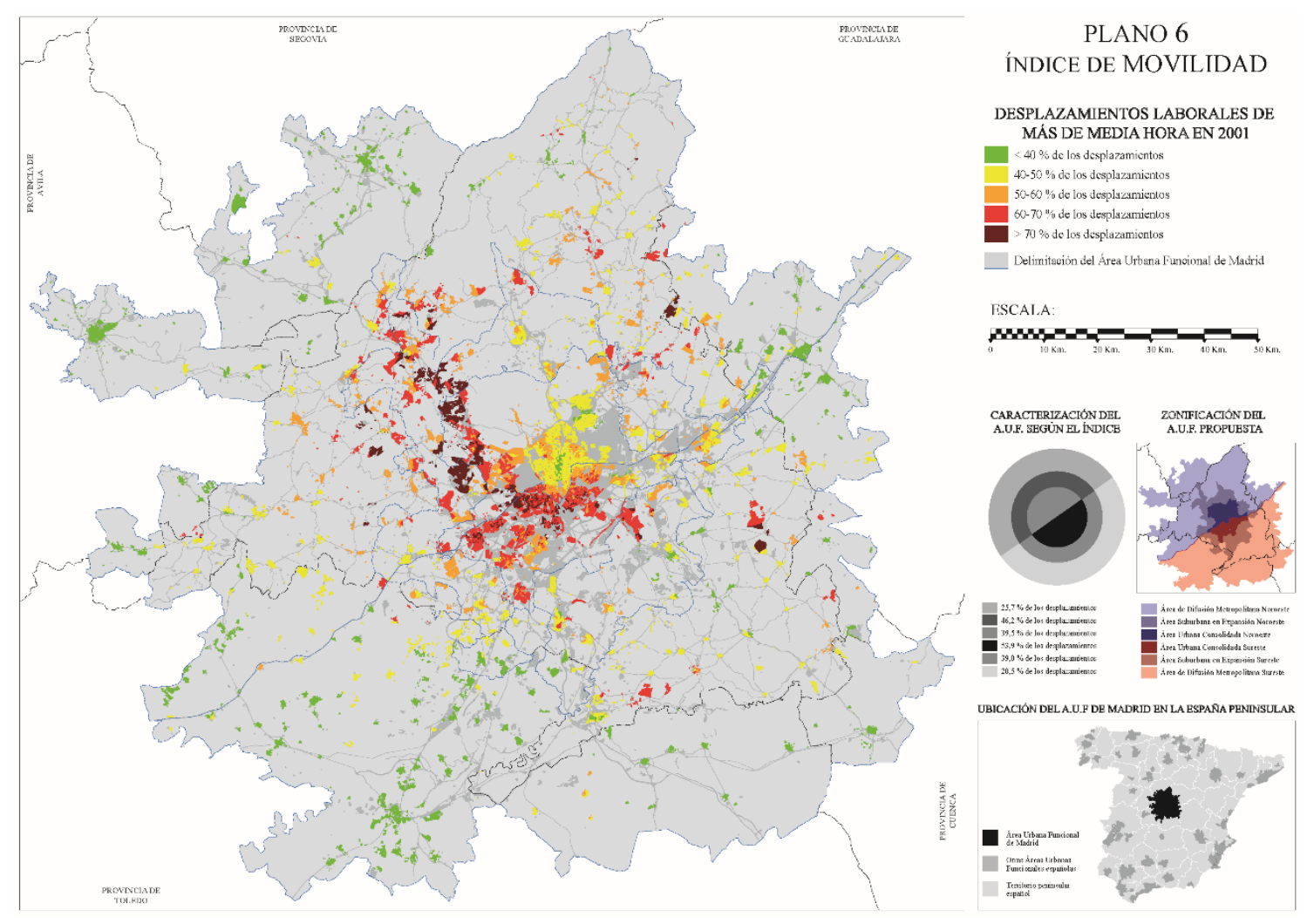

Figura 11: Territorialización de la movilidad laboral de larga duración en el A.U.F.M. (INE, 2001b)

Estos datos, junto a los menores índices de movilidad laboral peatonal, constatan algo que ya aventuraba el apartado anterior -recordemos el índice de vitalidad urbana-; las zonas consolidada sureste y de expansión noroeste son las más dependientes de un centro funcional que en realidad 
solo es ostentado por el área consolidada noroeste. Sin embargo, sus modelos de movilidad son antagónicos: mientras unos optan por el vehículo privado; otros, allá donde habita la mayoría, lo hacen por el transporte público, pero no parece que su mayor sostenibilidad a la hora de moverse les genere ninguna ventaja de velocidad.

\subsection{La vivienda como proyección del espacio social}


Figura 12: Territorialización de la superficie media útil de vivienda por habitante (INE, 2001b)

La ausencia de datos desagregados a nivel censal de la distribución de la renta nos enfrenta con serias dificultades a la hora de abordar la división social del espacio. Sin embargo, una mirada comparativa entre los últimos datos disponibles, que allá por el año 1997 facilitó la CAM, y el indicador de la superficie media útil de la vivienda por miembro del hogar en 2001 definen una distribución de los diferentes grupos sociales bastante pareja. Después de todo, la disparidad de renta y los elevados precios del mercado inmobiliario se conjugan bien como mecanismo de segregación espacial. Este indicador, intensificado además por el del número medio de hijos por hogar -que es mayor allá donde mejores condiciones de habitabilidad se dan; relación que induce a pensar en la merma de la natalidad como una resultante de situaciones de ajuste a las posibilidades materiales de cada hogar-, confirma de manera unívoca la validez del eje suroestenoreste como fractura del espacio social madrileño tanto en el área urbana consolidada como en la zona suburbana en expansión, mientras que no aparece -aún- en la zona de difusión.

\subsection{El suelo como recurso finito desigualmente distribuido}

El estudio del modelo de ocupación del suelo, sus densidades y su distribución, arroja datos contradictorios. Por un lado, como se observa en la Fig. 13, se ha producido una densificación residencial (medida en base a las superficies de suelo urbano: casco, ensanche y discontinuo del SIOSE, corroboradas a través del PNOA) de todas las zonas del área, que en conjunto ha pasado de 78 a 86 hab./Ha. Sin embargo, las diferencias de partida entre las zonas del arco noroeste y sureste se acentúan ya que la densificación ha sido más intensa en las zonas que de por sí ya eran más densas. A día de hoy, todas las zonas del sureste casi doblan la densidad residencial de las zonas del noroeste situadas en el mismo estadio del gradiente de intensidad urbana. Como 
EL ÁREA URBANA FUNCIONAL DE MADRID (1991-2011).

METODOLOGÍA Y RESULTADOS DE UNA PROPUESTA DE DELIMITACIÓN Y CARACTERIZACIÓN MULTICRITERIO Territorios en Formación | 2017 | N11 | TRABAJOS FIN DE MÁSTER - Estudios Urbanos

ejemplo, mientras que la densidad del consolidado norte es 135 hab./Ha., la del consolidado sur es de 246 hab./Ha.

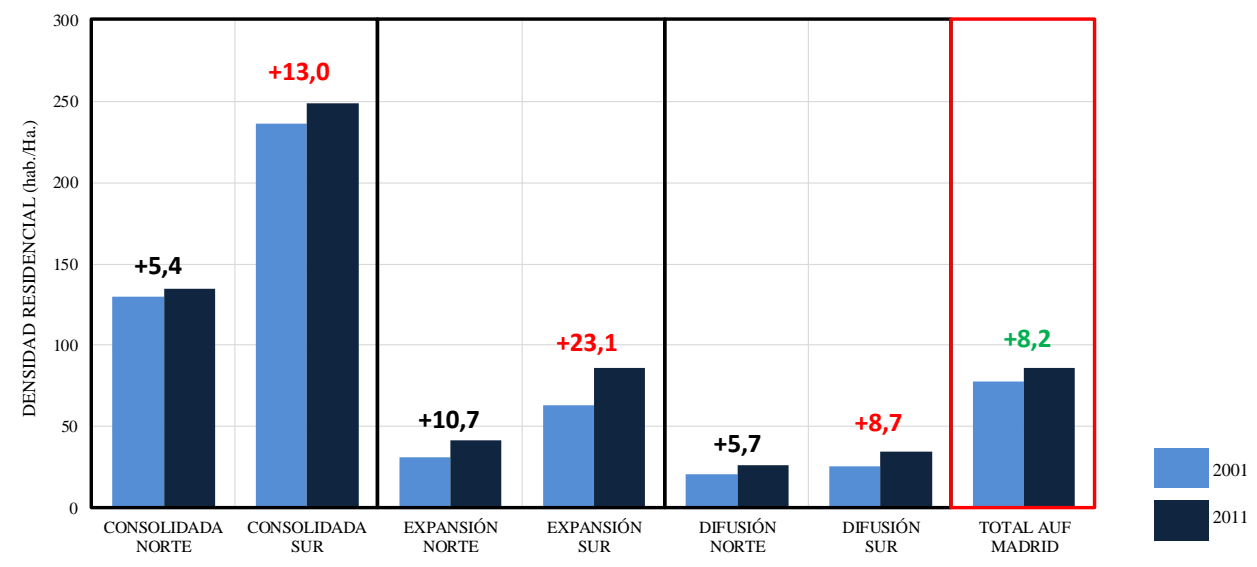

Figura 13: Evolución de la densidad residencial por zonas en el A.U.F.M entre 2001 y 2011: el número sobre las barras es el factor de densificación. (INE, 2001b y 2011b)

Idénticas consecuencias arroja el estudio de la evolución del coeficiente de Gini como medida de la desigualdad en la distribución del suelo residencial. En 2011 todas las zonas presentan una ocupación del suelo más igualitaria de la existente en 2001, sin embargo, son las zonas del arco sureste las que más han avanzado en un reparto menos desigualitario, con lo que se acentúa la validez del eje diferenciador del espacio social. En cualquier caso, solo la zona consolidada sur tiene un índice aceptable más cercano a la igualdad que a la desigualdad. Por dar un dato representativo sobre el asunto, en el área urbana consolidada noroeste solo el $15 \%$ de su población disfruta de más del $62 \%$ del suelo residencial total, definido por bajas densidades menores a los 100 hab./Ha.

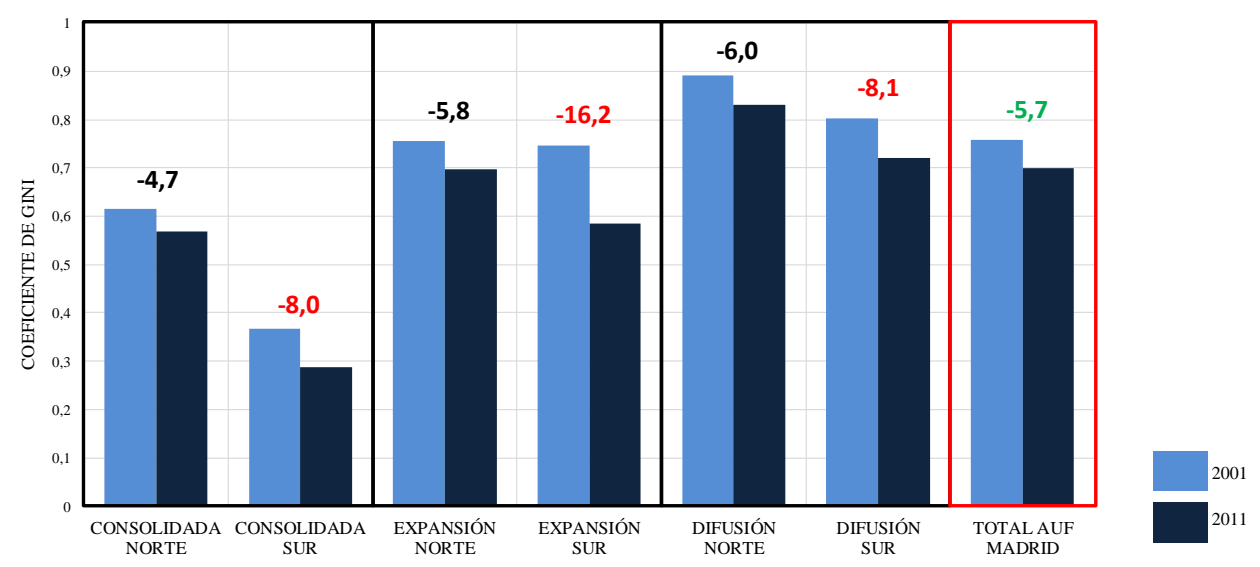

Figura 14: Evolución 2001-2011 del coeficiente de Gini -medida de la desigualdad en la distribución del suelo residencial-: el número sobre las barras es la diferencia porcentual. (INE, 2001b y 2011b)

Además, es pertinente apuntar un hecho que parece indicar el modelo evolutivo: el territorio que intensifica su anclaje al A.U.F.M. adquiere elementos de la caracterización propia del área consolidada. En realidad, es algo que ya se observó en la evolución de la artificialización de las coberturas del suelo: aunque de partida no se cumpla una caracterización antagónica entre el arco noroeste y el arco sureste, el proceso paulatino de integración en el A.U.F.M. conlleva que ésta 
comience a observarse. Como se aprecia en la Fig. 14, ambas zonas de expansión tenían en 2001 un índice de Gini equivalente, pero en 2011 la distancia que les separa es de 12 puntos.

\subsection{Algunos parámetros de la vulnerabilidad urbana}
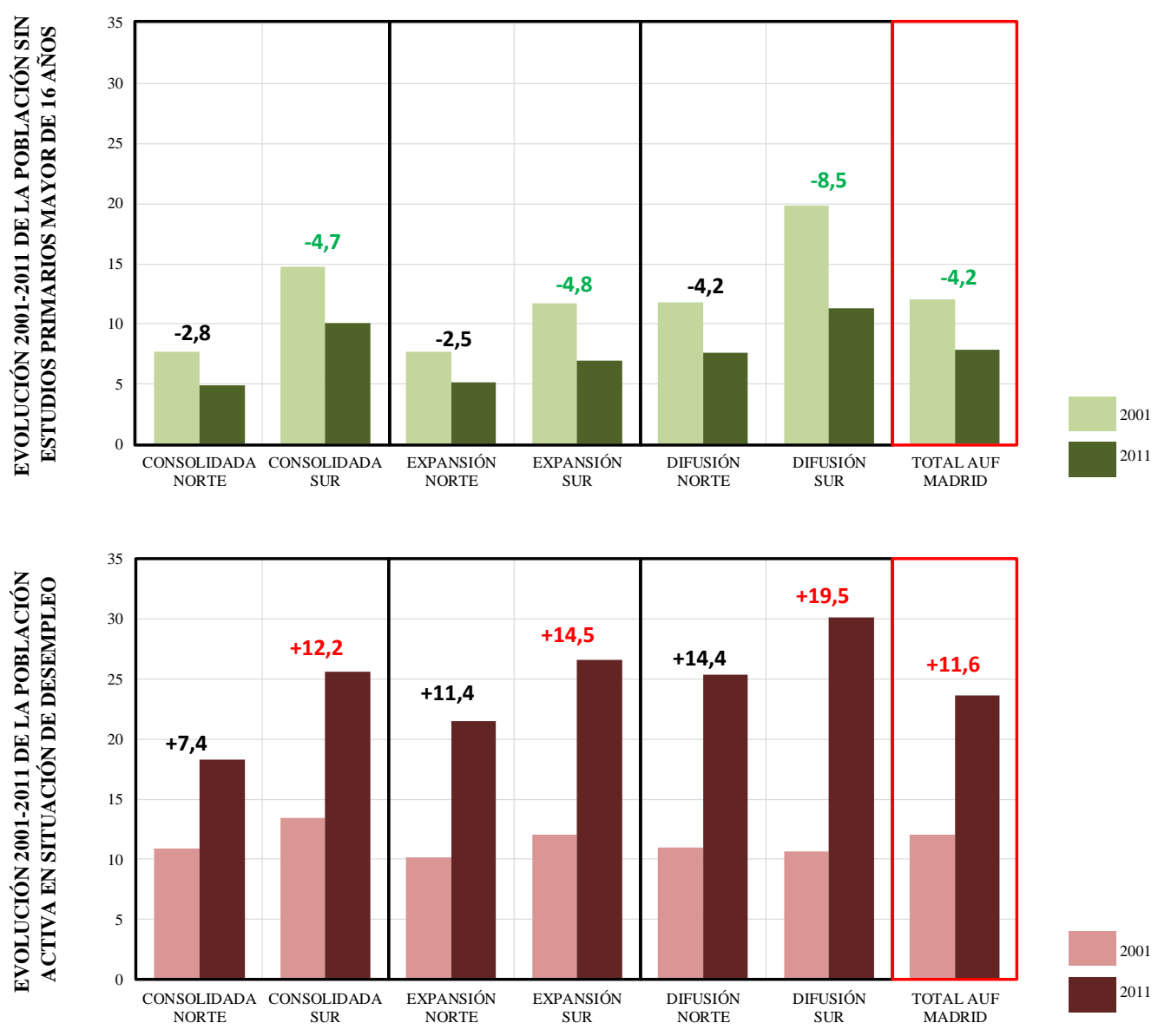

Figura 15: Parámetros de la vulnerabilidad en el A.U.F.M. (Fuente: INE, 2001b y 2011b)

La evolución de los patrones de vulnerabilidad vuelve a confirmar la validez de la división social propuesta. Si bien esto no ocurre con el indicador de población vulnerable por estudios, que mejora notablemente sus datos de 2001 a 2011 y además lo hace con mayor intensidad en las zonas más vulnerables del arco sureste -en consonancia con la fundación de dos universidades públicas en la zona consolidada sur y a nivel general, en todo el estado español, con la paulatina desaparición de las cohortes mayores menos formadas-; tampoco ello elimina que continúen las diferencias comparativas entre los ámbitos noroeste y sureste. Estás, además, se intensifican en un indicador mucho más preocupante: el desempleo (ver Fig. 15). Aunque la diferencia entre los dos arcos siempre estuvo latente, la situación general de crisis ha repercutido con muy desigual intensidad en los dos ámbitos, siendo mucho más contundente en las zonas del arco sureste y a medida que disminuye el gradiente de intensidad urbana - las zonas de difusión-. Este dato constata la relación entre terciarización -un sector con un alto grado de diversificación- del empleo y resiliencia. Las zonas con mayor población residente ocupada en servicios -noroeste consolidado y en expansión- han sido las menos castigadas (ver Fig. 16). Además, esto pone también de manifiesto que la dependencia funcional de los territorios más periféricos del A.U.F.M, los somete a un mayor grado de vulnerabilidad ante la aparición de coyunturas económicas poco virtuosas. 
EL ÁREA URBANA FUNCIONAL DE MADRID (1991-2011).

METODOLOGÍA Y RESULTADOS DE UNA PROPUESTA DE DELIMITACIÓN Y CARACTERIZACIÓN MULTICRITERIO Territorios en Formación | 2017 | N11 | TRABAJOS FIN DE MÁSTER - Estudios Urbanos

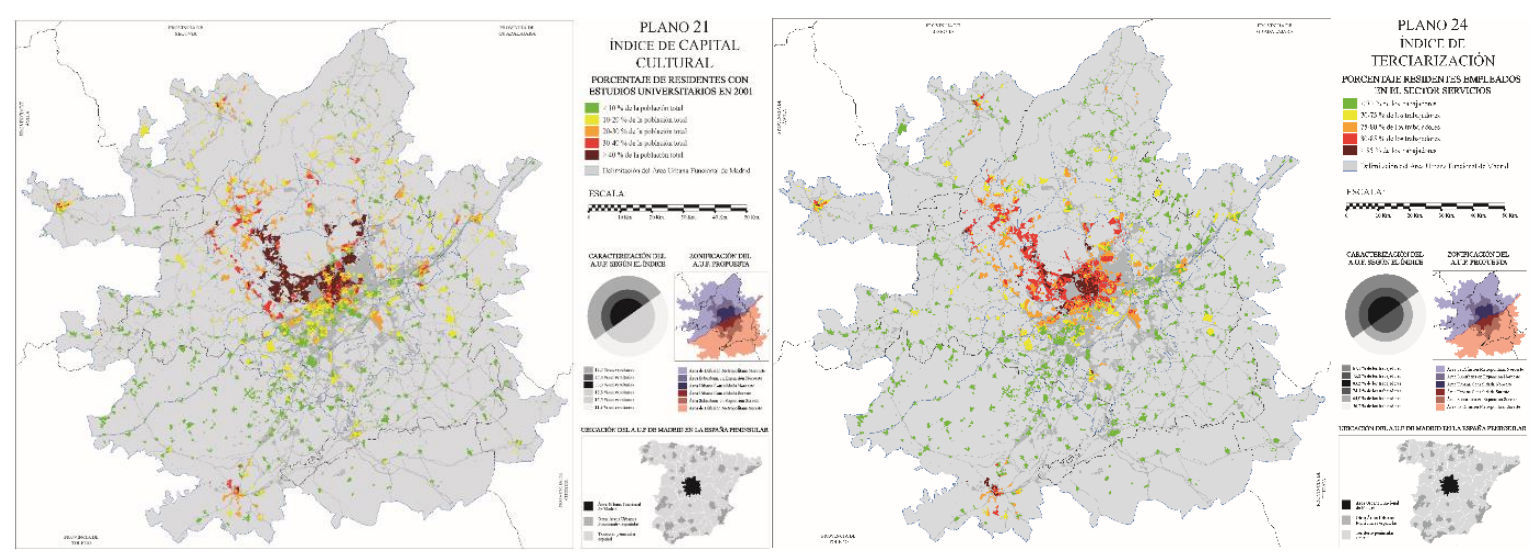

Figura 16: Los índices inversos de la vulnerabilidad por falta de estudios y desempleo: el porcentaje de titulados universitarios y la terciarización del empleo (Fuente: INE, 2001b)

\section{Conclusiones}

El desarrollo de esta investigación ha dejado patente la conveniencia de un enfoque que se centre en los procesos constitutivos de lo urbano más allá de los bordes administrativos apriorísticos. Además, constata el acierto de la metodología de delimitación y zonificación empleadas en el área urbana funcional madrileña. Respecto a los resultados, en síntesis, las conclusiones fundamentales a tenor de ellos son tres:

En primer lugar, los datos obtenidos reflejan la pervivencia del eje definido por la A-5, el arco sureste de la M-30 y la A-2 como fractura divisoria del espacio social madrileño, válido también en su área funcional. En esta investigación se ha observado que cuando esta dicotomía aún no existe en las zonas en fases más o menos acusadas de integración, el propio modelo evolutivo de los procesos urbanos que caracterizan al A.U.F.M. genera su aparición. Con respecto a las zonas suburbanas en expansión, donde se observa esta intensificación de la fractura, si bien las zonas del noroeste pueden explicar los menores índices de artificialización en base a sus más protegidos suelos naturales -frente a un sureste eminentemente agrario-; la aparición de una brecha en cuanto al modelo de movilidad, densidad, distribución del suelo y vulnerabilidad urbana va más allá de tal evidencia. Todo ello mostraría que la definición de esta fractura -noroeste/sureste- puede ser enunciada como proceso constitutivo del territorio urbano madrileño.

En segundo lugar, los análisis han indicado que los procesos de integración urbana han tenido distintos ritmos en las zonas suburbana noroeste y sureste. Mientras que en el noroeste la capacidad de atracción demográfica y la puesta en carga de nuevo suelo fueron mayores en la primera década de estudio, de 1991 a 2001; en el sureste ocurre lo contrario, la intensidad de los procesos aumenta incrementalmente en la segunda década, de 2001 a 2011. No es descabellado asumir, por tanto, que el parón en seco del desenfrenado proceso urbanizador ha dejado una huella más profunda justo en esta zona. En todo caso, hasta 2011 el insostenible proceso de urbanización extensiva no paró de crecer incrementalmente. Parte de los resultados ya están ahí, como ha demostrado la menor resiliencia de estas zonas ante la crisis.

Por último, si entendemos el área funcional como un núcleo de actividad y su territorio de influencia, los resultados de esta investigación indican que dicho papel nuclear en el A.U.F.M. no es desempeñado de igual forma por toda su área consolidada sino en mayor medida por su ámbito noroeste. Otro factor de insostenibilidad: incluso la zona más densa y poblada -la consolidada 
sureste- presenta un cierto grado de dependencia funcional. Esto es, conjugar actividad y residencia continúa siendo una tarea a cumplir.

La repetición de esta metodología en otras áreas funcionales españolas abriría el camino a una necesaria comparativa entre sus diferentes modelos evolutivos, algo que ayudaría a tener una mayor comprensión de nuestra realidad urbana. Otras posibles vía de continuación que introduce este trabajo pasan por cruzar algunos de los datos obtenidos a nivel censal. Por ejemplo, explorar los diferentes "mixes" de movilidad en relación a la calidad residencial, el nivel de capital cultural o a través de datos desagregados por género. Además, la posibilidad de generar dichos indicadores con un nivel más desagregados permitirá aumentar el grado de discriminación espacial de las zonas a caracterizar.

En cuanto a las conclusiones de tipo propositivo, lo que demuestra este trabajo es la necesidad de abordar la planificación y gestión de nuestras ciudades en base a una realidad que no se está teniendo en cuenta, o al menos, no lo suficiente. Es imprescindible que toda toma de decisiones se base en un conocimiento exhaustivo de la realidad, sea cual sea el futuro que anticipe. El funcionamiento interrelacionado que emana de las áreas urbanas funcionales exige una coordinación interadministrativa que supondrá un gran reto para las administraciones de nuestros ayuntamientos y comunidades autónomas, un reto para el que tal vez no estén preparadas. La toma de decisiones sin contar con "un vecindario" íntimamente interrelacionado, y la oferta de máximos de suelo residencial por parte de todos los entes municipales del área funcional, -en busca de atraer población compitiendo con el resto-, ha tenido unas nefastas repercusiones sobre la sostenibilidad del sistema. Es necesario que las diferentes administraciones tomen muy en serio los cada vez más delicados equilibrios presentes en el área funcional madrileña. La descoordinación y la competición suponen un riesgo para la sostenibilidad de nuestros sistemas urbanos. Las respuestas han de ser consensuadas y pactadas, porque si cada cual continúa tomando sus propias decisiones, sin contar con unas estrategias territoriales de conjunto, las desigualdades y los desequilibrios no dejarán de crecer.

\section{Referencias}

AYUNTAMIENTO DE MADRID, DIRECCIÓN GENERAL DE ESTADÍSTICA (2014): “Dimensión territorial y socioeconómica de la Región Metropolitana de Madrid", en Barómetro de Economía de la Ciudad de Madrid, 39, 104-130, disponible en http://www.madrid.es/UnidadesDescentralizadas/UDCObservEconomico/BarometroEconomia/2014/Primer\%20tri mestre/Ficheros/39\%20barometro_Completo.pdf, fecha de consulta: 22-05-2016

BRAUDEL, F. (1984): Civilización material, economía y capitalismo. Siglos XV-XVIII. 3. El tiempo del mundo. Madrid: Alianza Editorial

BRENNER, N. (2013): “Theses on urbanization», en Public culture 25, 1.69, 85-114

BURNS, M.C. ET AL. (2009): “El sistema metropolitano de la macrorreción de Madrid», en Urban, 14: 72-79

DUPUY, G. (1998): El urbanismo de las redes. Teorías y métodos. Barcelona: Oikos-Tau

EUROSTAT (2016): Urban Audit Cities. Functional Urban Areas, disponible en http://ec.europa.eu/eurostat/statistical-atlas/gis/viewer/?myConfig=REF-UA.xml, fecha de consulta: 15-01-2016

FERIA TORIBIO, J. M. (2008): "Un ensayo metodológico de definición de las áreas metropolitanas en España a partir de la variable residencia-trabajo", en Investigaciones geográficas, 46: 49-68 


\section{EL ÁREA URBANA FUNCIONAL DE MADRID (1991-2011). METODOLOGÍA Y RESULTADOS DE UNA PROPUESTA DE DELIMITACIÓN Y CARACTERIZACIÓN MULTICRITERIO Territorios en Formación | 2017 | N11 | TRABAJOS FIN DE MÁSTER - Estudios Urbanos}

FISHMAN, R. (1990): “America's New City”, en The Wilson Quarterly, 14(1):24-55

INSTITUTO GEOGRÁFICO NACIONAL (1990, 2000 Y 2006): Ocupación del suelo. Proyecto Corine Land Cover. Coordination of Information of the Environment. Agencia Europea del Medio Ambiente. Disponible en https://www.ign.es/ign/layoutin/corinelandcover.do, fecha de consulta: 15-01-2016

INSTITUTO NACIONAL DE ESTADÍSTICA (2001a y 2011a): Áreas Funcionales Urbanas. Disponible en http://www.ine.es/ss/Satellite?L=es_ES\&c=INEPublicacion_C\&cid=1259944561392\&p=1254735110672\&pagen ame=ProductosYServicios\%2FPYSLayout\&param1=PYSDetalleGratuitas, fecha de consulta: 10-01-2016

- (1991, 2001b y 2011b): INEbase: Cifras de Población y Censos Demográficos. Disponible en http://www.ine.es/inebmenu/mnu_cifraspob.htm, fecha de consulta: 15-02-2016

LEAL MALDONADO, J. y DOMÍNGUEZ PÉREZ, M. (2008): "Transformaciones económicas y segregación social en Madrid", en Ciudad y territorio, XL (158): 703-725.

MINISTERIO DE FOMENTO (2015): Atlas estadístico de las áreas urbanas. Disponible en http://www.fomento.gob.es/MFOM/LANG_CASTELLANO/DIRECCIONES_GENERALES/ARQ_VIVIENDA/SUELO_Y_POLI TICAS/Atlas/, fecha de consulta: 15-01-2016

MUMFORD, L. (1965): La ciudad en la Historia. Sus orígenes, transformaciones y perspectivas. Buenos Aires: Infinito

NEL-LO, O. (1998): "Los confines de la ciudad sin confines. Estructura urbana y límites administrativos en la ciudad difusa", en Monclús, 1998:35-57

OBSERVATORIO METROPOLITANO (2007): Madrid ¿la suma de todos? Globalización, territorio, desigualdad. Madrid: Traficantes de sueños

ROCA-CLADERA, J. (2003): “La delimitación de la ciudad: ¿una cuestión imposible?», en Ciudad y Territorio. Estudios Territoriales, 135: 17-36

RUIZ, F (2001): AUDES: Áreas Urbanas de España. Disponible en http://alarcos.esi.uclm.es/per/fruiz/audes/index.htm, fecha de consulta: 15-02-2016

SASSEN, S. (2014): Expulsions. Cambridge: Belknap Harvard 
